\title{
Economic comparison of insemination and culling policies in commercial sow herds, assessed by stochastic simulation
}

\author{
E. H. P. HOUBEN, J. G. M. THELOSEN, R. B. M. HUIRNE \& \\ A. A. DIJKHUIZEN
}

Department of Farm Management, Wageningen Agricultural University, Hollandseweg 1, NL 6706 KN Wageningen, Netherlands

Received 9 May 1989; accepted 9 April 1990

\begin{abstract}
In a stochastic sow herd simulation model the economic effects of three insemination and culling policies with a potential practical application were compared. Culling policies under consideration showed to have considerable effect on technical and economic results, whereas insemination policies did not.
\end{abstract}

Keywords: simulation model, sows, economics, insemination, culling

\section{Introduction}

Insemination and culling are frequent and important management decisions in livestock farming. In previous research, stochastic simulation was used to evaluate the economics of these decisions in dairy herds (Dijkhuizen \& Stelwagen, 1988). In this paper a similar approach is developed and presented for commercial sow herds.

In commercial sow herds, most sows are culled not because they are no longer able to (re)produce, but because replacement gilts are expected to offer a better economic return (Dijkhuizen et al., 1989). The potential effects of detailed insemination and culling guides under field conditions cannot be derived from actual farm data only. The necessary experiments would be costly, especially if a comparison is done with more extreme alternatives, and they would take years to complete. Therefore, a stochastic simulation model on animal level was developed.

\section{Material and methods}

The fundamental concept of the model was developed by de Roo (1987), who simulated a nucleus pig farm. This model has been modified to simulate typical commercial sow herds. Moreover, an additional module was developed to calculate the economic effects. 
The underlying structure of the current model is that individual sows are 'moved' forward through time, modifying the status of each sow according to the outcome of various events and management decisions. With a time-step of one week, changes in the herd can continually be followed at annual intervals. The first 10 years are used to stabilize the initial situation and the next 10 years concern the experimental period in which different policies are compared. For each alternative, 20 runs of calculations are carried out to obtain statistically reliable results.

In order to closely imitate real farm conditions, several events and effects of decisions are involved in a stochastic manner, i.e. as random samples from appropriate probability distributions rather than as fixed values. Age at first oestrus, interval weaning to oestrus, reproductive performance (ovulation rate, number of piglets born and weaned) and fertility problems (no oestrus, abortion) are simulated in a stochastic manner. Deterministic parameters are feed cost, cost of replacement gilts, slaughter value of culled sows and prices of feeder pigs. Repeatability in litter size in two subsequent parities has been established on 0.2 (Knap, 1985). Parity is synonymous with sow production cycle and ends at the time of weaning.

In the model, culling is divided into unplanned disposal (e.g. fertility, diseases and leg problems) and planned disposal (e.g. selection on reproduction). To cover a variety of insemination and culling policies with a potential practical application, different policies are chosen to be compared in the experimental period of the model (years 11 to 20). The following three insemination policies are compared: (1) a maximum number of three inseminations per parity for all sows, (2) a maximum number of inseminations depending on parity number; sows in parities 1 to 4: three inseminations, sows in parities 5 to 7: two inseminations, other sows and gilts: one insemination, and (3) a number of inseminations (with a maximum of three) depending on the sows' Retention Pay-Off (RPO), developed in previous research (Dijkhuizen et al., 1989). The RPO is an economic index, which makes it possible to rank sows on future profitability: the higher the RPO, the more valuable the sow. Under all policies, replacement gilts are assumed to be available with average genetic value.

Also three culling policies (planned disposal) are compared within a total disposal rate of 55\%: (A) culling of the eldest weaned sows; (B) culling of weaned sows with the lowest RPO; in case of oversupply of replacement gilts additional sows are culled; and (C) culling of weaned sows with the lowest RPO without a predetermined preference for available replacement gilts above sows (replacement gilts can also be culled).

Insemination policies are compared using culling policy $\mathrm{C}$, and culling policies using insemination policy 1 . All simulations are carried out within a herd size of 150 sows.

\section{Results}

The three insemination policies under consideration did not differ significantly in technical and economic results (Table 1). This finding agrees with the low level of repeatability in fertility problems within sows, but will also be affected by the maximum of three inseminations per parity presumed in the model for all policies. 
Table 1. Results of insemination policies $(1,2,3)$ and culling policies $(A, B, C$, ) with a total disposal rate of $55 \%$ in a herd with 150 sow-places.

\begin{tabular}{|c|c|c|c|c|c|}
\hline & \multirow{2}{*}{$\begin{array}{l}\text { Basic results } \\
1, C\end{array}$} & \multicolumn{4}{|c|}{ Contrast with basic results } \\
\hline & & $2, \mathrm{C}$ & $3, \mathrm{C}$ & $1, \mathrm{~A}$ & $1, \mathrm{~B}$ \\
\hline Litters/sow/year & 2.25 & 0.00 & 0.00 & $-0.01^{*}$ & 0.00 \\
\hline Pigs weaned/sow/year & 19.74 & +0.05 & -0.01 & $-0.18^{* *}$ & 0.07 \\
\hline Profit/sow (Dfl.) & 560 & +2 & -1 & $-12^{* *}$ & -5 \\
\hline Profit/herd (Dfl.) & 78894 & -29 & -456 & $-2857^{* *}$ & $-1430^{* *}$ \\
\hline
\end{tabular}

Student's $t$-test $\left(2\right.$ and 3 versus $1, \mathrm{~A}$ and B versus $\mathrm{C}$ ): ${ }^{*} P<0.05,{ }^{* *} P<0.01$

More effects were seen by changing the culling policies (Table 1). The technical results of policy $\mathrm{A}$, in which the sows are culled on age only, appear to be the worst. Policy $C$ provides the highest economic profit. Unconditional introduction of available gilts (policy B) results in a lower economic benefit than a conditional introduction (policy $\mathrm{C}$ ). Additional calculations showed that planned disposal should be at least $10 \%$ to yield positive economic effects of an advanced culling policy $(\mathrm{C})$.

\section{Final remarks}

Sow insemination and culling decisions also have an impact on animal flows through the different housing facilities. Therefore, research is underway to develop a computer model especially focussed on animal movement strategies on swine breeding farms.

\section{Acknowledgements}

The authors are indebted to H. A. M. van der Steen and A. G. de Vries, Department of Animal Breeding, for their useful advice in developing the model.

\section{References}

Dijkhuizen, A. A. \& J. Stelwagen, 1988. An economic comparison of four insemination and culling policies in dairy herds, by method of stochastic simulation. Livestock Production Science 18: 239-252.

Dijkhuizen, A. A., R. M. M. Krabbenborg \& R. B. M. Huirne, 1989. Sow replacement: a comparison of farmers' actual decisions and model recommendations. Livestock Production Science 23: 207-218

Knap, P. W., 1985. Selection for fertility in Dutch pig herdbook breeding. Aggregate genotype, selection index, and the use of information from relatives. 37th Annual Meeting of the EAAP, Budapest, paper GP 3.12, 16 pp.

Roo, G. de, 1987. A stochastic model to study breeding schemes in a small pig population. Agricultural Systems 25: 1-25. 
This synopsis is based on a student thesis entitled 'De invloed van het aan-en afvoerbeleid op de resultaten van een zeugenbedrijf; een simulatie van een vermeerderingsbedrijf' by E. H. P. Houben \& J. G. M. Thelosen, Department of Farm Management, Wageningen Agricultural University, 1989, 72 pp., 26 tabs, 17 figs, 27 refs, 4 apps, in Dutch. Available as paper copy (order R103, $f$ 20,-including postage) at: NARD, c/o Pudoc, P.O. Box 4, 6700 AA Wageningen (telex 45015 bluwg $\mathrm{nl}$ ). 